\title{
Araknoid Kistler ile İlişkili Subdural Hematomlar: İki Olgu Sunumu
}

\author{
Subdural Hematoma Associated with Arachnoid Cyst: Reported of Two \\ Mustafa Kaya, Davut Ceylan, Tibet Kaçıra \\ Department of Neurosurgery, Sakarya University Training and Research Hospital, Sakarya, Turkey
}

Yazışma Adresi / Correspondence:

Mustafa Kaya

Department of Neurosurgery, Sakarya University Training and Research Hospital, Sakarya, Turkey 54010

T: +905426945001Ｅ-mail: mkaya2834@gmail.com

Geliş Tarihi / Received : 16.02.2021 Kabul Tarihi / Accepted : 06.07.2021

Orcid:

Mustafa Kaya: https://orcid.org/0000-0001-5548-4944

Davut Ceylan: https://orcid.org/0000-0002-2056-2786

Tibet Kaçira: https://orcid.org/0000-0003-4870-7550

( Sakarya Tip Dergisi / Sakarya Med J 2021, 11(3):669-674) DOI: 10.31832/smj.881421

Öz

Araknoid kistler, meninkslerin intrakranial beyin parankimi dıșında kalan konjenital malformasyonlarıdır. Birçoğu tesadüfen saptanırlar. Kafa travması sonrası subdural hematoma sebep olabilirler. Literatürde, araknoid kistler ile ilişkili subdural hematom tedavisinde çeșitli cerrahi yöntemler önerilmiştir. Bunlar; burr hole ya da kraniotomi ile subdural hematom boşaltılması, endoskopiyle kist fenestrasyonu ve subdural hematom boşaltılması, burr hole ya da kraniotomiyle subdural hematom boşaltılması sonrası kistoperitoneal şant takılmasıdır. En sık kullanılan uygulama burr hole ile subdural hematom boşaltılmasıdır. Diğer tedavi seçenekleri burr hole ile subdural hematom drenajının başarısız olduğu durumlarda önerilmektedir. Biz bu olgu sunumunda, burr hole ile subdural hematom drenajı yaparak tedavi ettiğimiz iki hastamızın sonuçlarımı bildirmek istiyoruz.

Anahtar Araknoid kist; Subdural hematom; Burr hole drenajı

kelimeler

Abstract

Arachnoid cysts are congenital malformations of the meninges located outside the intracranial brain parenchyma. Many of them are detected by chance. They can cause subdural hematoma after head trauma. Various surgical methods have been proposed in the literature in the treatment of subdural hematoma associated with arachnoid cysts. These methods are; Subdural hematoma evacuation with burr hole or craniotomy, cyst fenestration and subdural hematoma evacuation by endoscopy, cystoperitoneal shunt insertion after subdural hematoma evacuation with burr hole or craniotomy. The most common application among these methods is subdural hematoma evacuation with burr hole. Other treatment options are recommended in cases where subdural hematoma drainage fails with burr hole. In this case report, we would like to report the results of our two patients who we treated by draining subdural hematoma with burr hole.

Keywords Arachnoid cyst; Subdural hematoma; Burr hole drain 


\section{GİRIŞ}

İnrakranial araknoid kistler yaygın olarak orta fossada yerleșen beyin omurilik sıvısı (BOS) ya da BOS benzeri berrak sıvı içeren konjenital ekstraaksiyal lezyonlardır. ${ }^{1}$ İntrakranial kitlelerin yaklaşık olarak \%1 ini oluştururlar..$^{2-5}$ Araknoid kistlerin neden orta fossada daha sık olduğu tam olarak bilinmemektedir ve çoğu asemptomatiktir. Genellikle kafa travması ya da diğer nedenler için çekilen kranial bilgisayarlı tomografi (BT) ve manyetik rezonans (MR) ile insidantal olarak tanı konur. Orta fossa araknoid kistlerin (AK) bazıları baş ağrısı, nöbet ya da intrakranial kanamaya sebep olmaktadır. ${ }^{1}$ AK komplikasyonlarından biri de kronik subdural hematomdur (KSDH) ${ }^{3,5-7}$ AK ile ilişkili KSDH'lar travmaya bağlı ya da travma tanımlanamasa da yaşlılarda ve infantlarda daha sık, büyük çocuklarda ve erişkinlerde daha az görülür.

KSDH ile ilişkili AK lerde kanama mekanizması tam olarak bilinmemekle birlikte, kanamaya kist içerisindeki sıv1nın veya kist duvarını çevreleyen damarların sebep olduğu söylenmektedir. ${ }^{5-7}$ Bazı yazarlar dura ve araknoid membran arasındaki yapıya vurgu yapsalar da operasyon sırasında hematomdan dolayı tam olarak kanamanın nereden kaynaklandığını bulmak mümkün olmamaktadır.

AK'ler ile ilişkili KSDH'da literatürde yazarların çoğu sadece subdural hematom (SDH) drenajını önerirken, bazı yazarlar da AK'lere de müdahale etmeyi öneriyorlar. Biz bu çalışmamızda sadece SDH drenajı ile tedavi ettiğimiz AK ile ilişkili SDH’ı olan iki çocuk olgumuzu paylaşıyoruz.

\section{Olgu sunumları}

Hastaların hepsine tıbbi verilerinin yayınlanabileceğine ilişkin olarak ayrıntılı bilgi verildi ve hastalardan yazılı, imzalı izin belgesi alındı.

\section{Olgu 1}

19 yaş erkek hasta motorsiklet kazası nedeniyle kafa travması sonrası baş ağrısı gelişmesi sonucu acil servise başvurdu. Çekilen kranial BT'de sol frontotemporoparyatal bölgeye açılan ve sol orta fossayı tamamen dolduran, $1 \mathrm{~cm}$ orta hat şiftine yol açan Galassi Tip 2 araknoid kist izlendi (Şekil 1a). Nörolojik muayenesinde baş ağrısı dışında patoloji izlenmeyen hastanın, kanama diatezi açısından yapılan INR, PT, APTT ve kanama zamanı testleri normal s1nırlarda izlendi. Baş ağrısı azalan ve kontrol kranial BT’de değişiklik olmayan hasta taburcu edilerek takibe alındı. Takibinin 15. gününde baş ağrısı, bulantı, kusma ve bilinç bulanıklığı ile tekrar tarafımıza başvuran hastaya yapılan kranial BT görüntülemesinde subdural aralıktaki araknoid kistin kanadığı ve subakut-kronik subdural hematoma dönüştüğü izlendi (Şekil 1b). Hastanın başvuru sırasında bilinci uykuya meyilli, GKS:13, sağ hemiparezisi mevcuttu. Sol frontal ve paryetal bölgelere açılan iki adet burr hole ile SDH boşaltıldı. Postop yapılan kontrol kranial BT'de orta hat şiftinin düzeldiği, hematomun boşaltıldığı izlendi (Şekil 1c). Ameliyat sonrasında hasta; bilinci açık, oryantasyonu tam ve sağ hemiparezisi tamamen düzelmiş olarak taburcu edildi.

\section{Olgu 2}

7 yaş erkek hasta acil servise nöbet geçirme şikâyeti ile getirildi. Travma öyküsü saptanmayan hastaya yapılan kranial BT ve MR'da sol frontotemporopariatel bölgeye açılan yaygın septalarla birbirinden ayrılan KSDH'la ilişkili Galassi Tip 3 araknoid kist izlendi (Şekil 2a). Hastanın nörolojik muayenesinde bilinci açı, oryantasyonu tam, patolojik olarak da sağ hemiparezisi mevcuttu. Kanama diatezi açısından yapılan INR, PT, APTT ve kanama zamanı testleri de normal sinırlarda izlendi. Operasyona alınan hastaya sol frontal ve pariyetal bölgeye açlan iki adet burr hole ile SDH'u boşaltıldı. Ameliyat sonrası genel durumu ve motor defisiti düzeldi. Postoperatif 2. gününde yap1lan kranial BT'de hematomun boşalmış olduğu gözlendi. Klinik olarak da sağ hemiparezisi tamamen düzelen hasta taburcu edildi. 


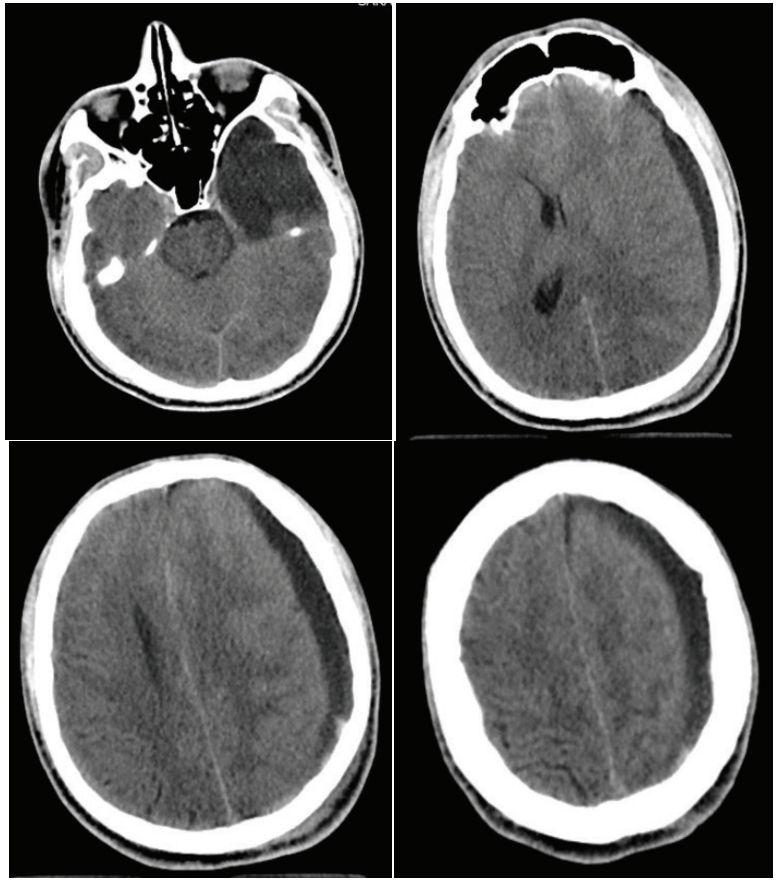

Şekil 1a: Olgu 1 travma sonrası ilk Kranial BT, sol temporal bölgede yerleşen $A K$ in temporaparyatal bölgede subdural alana rüptürü. Kist içeriği hipodens görünüyor.
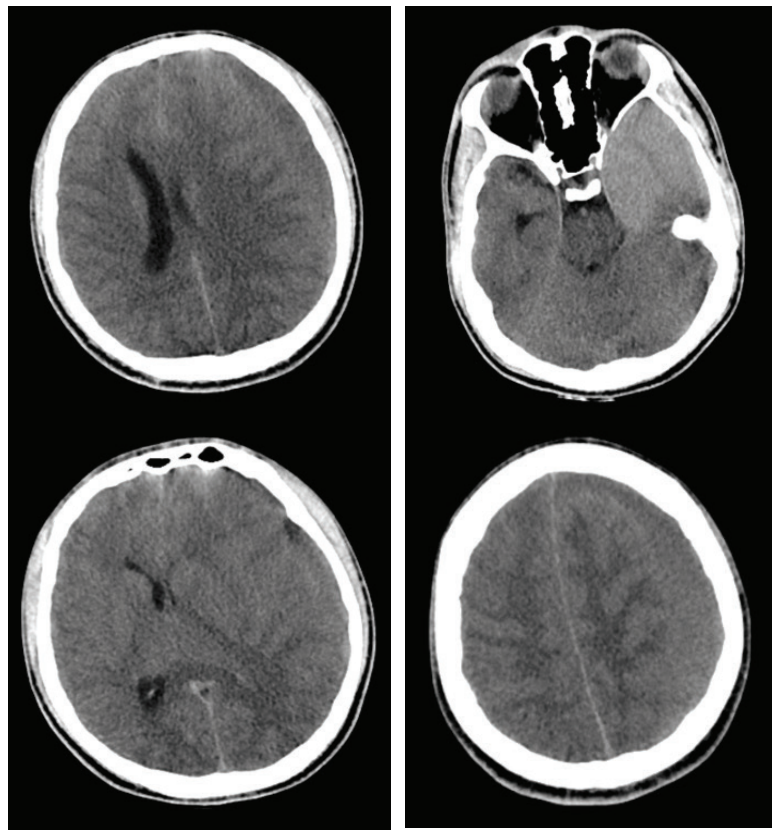

Şekil 1b: Olgu 1 Travma sonrası 15. gün Kranial BT de Şekil 1a'da görülen AK ve temporoparyetal alana açılan sıvı içeriği hiper-izodens forma dönüştü.

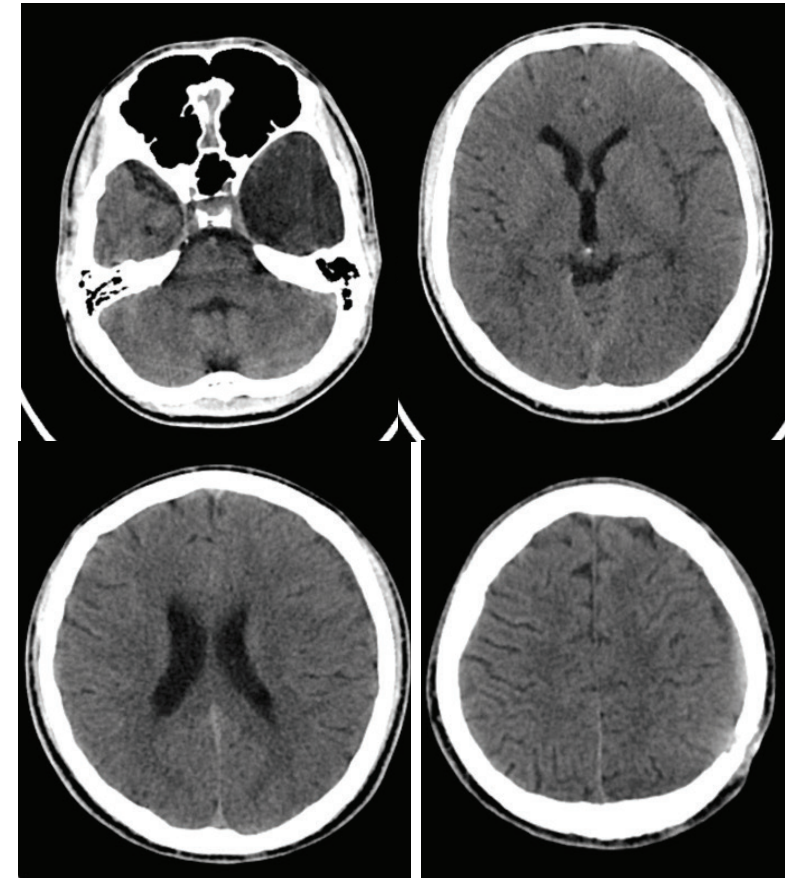

Şekil 1c: Olgu 1 Postop 1. ay Kranial BT. Sadece temporal bölgede kist sivisının görülmesi. Hemotomun tamamen rezorbe olduğu izlenmekte.
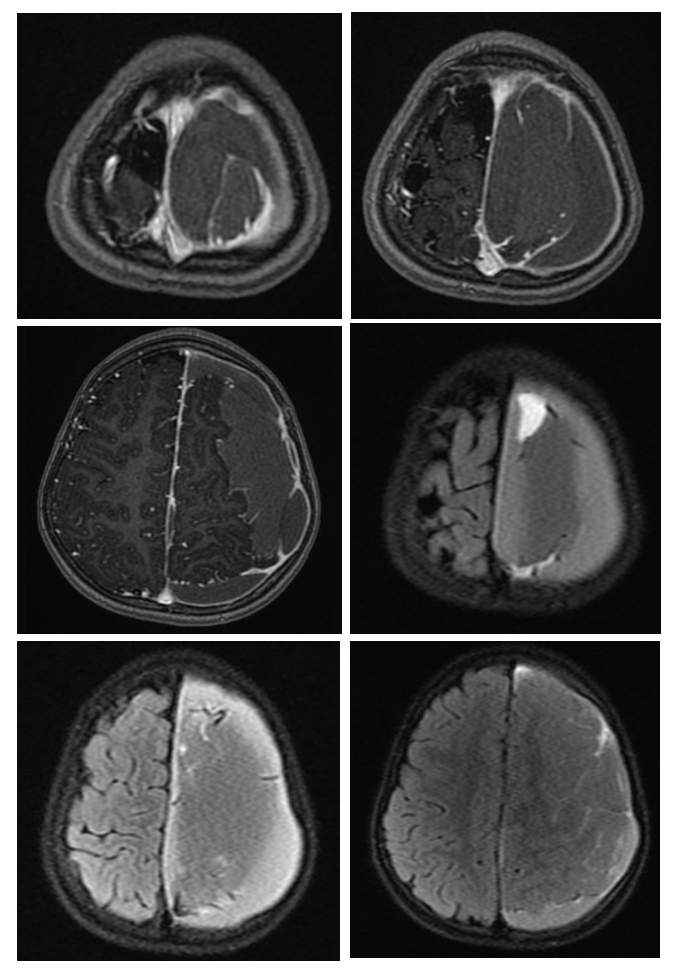

Şekil 2a: Olgu 2 Nöbet sonrası çekilen Kranial MR 

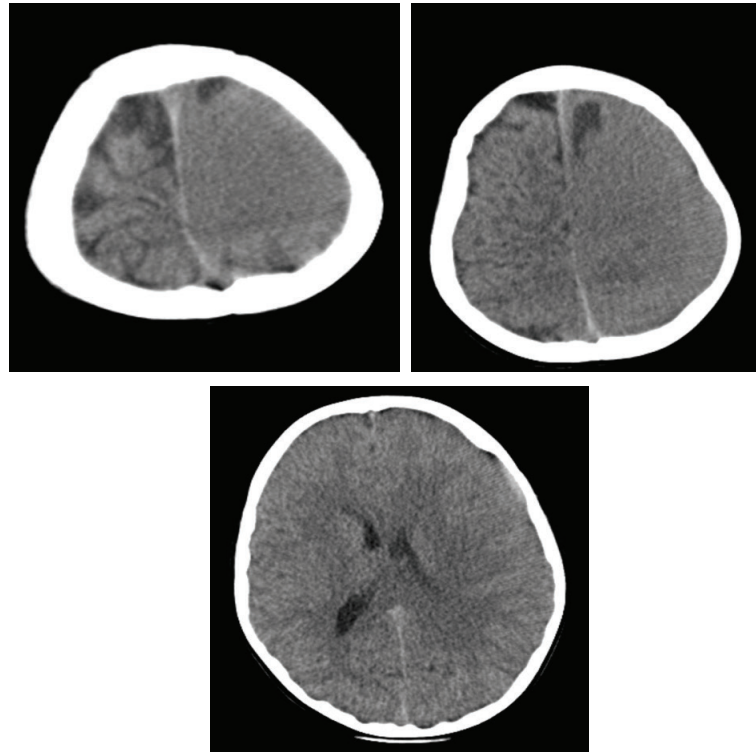

Şekil 2b: Olgu 2 Nöbet sonrası çekilen Kranial BT
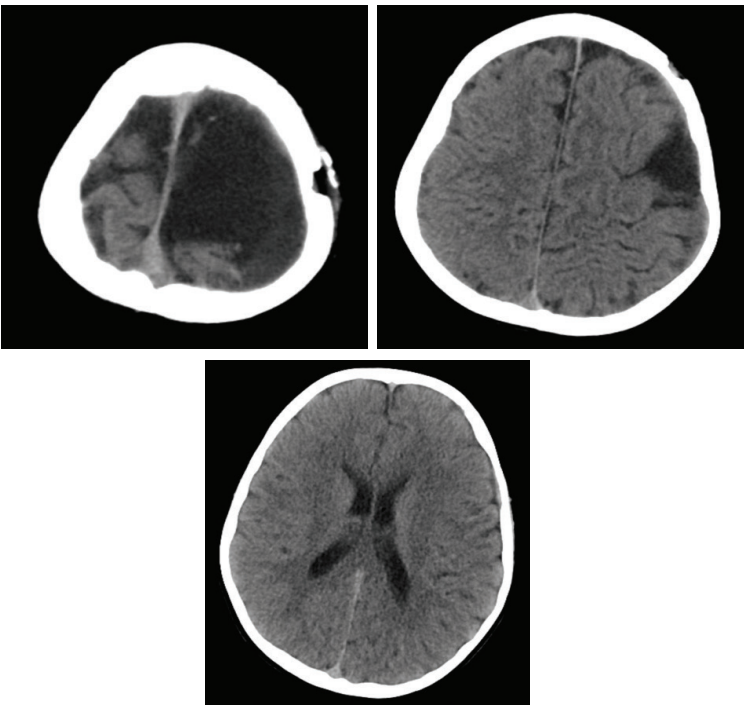

Şekil 2c: Olgu 2 Postop 1. ay çekilen Kranial BT

TARTIŞMA

AK’ler, içi BOS ya da BOS benzeri sıvıyla dolu, duvarları araknoid membranlardan oluşan konjenital ekstra aksial (beyin parankimi dışında kalan) intraaraknoidal kistlerdir. ${ }^{3}$ Sebebi tam olarak bilinmemekle birlikte en yaygın kabul gören görüş, BOS akımı tarafından ilk perimedüller ağın subaraknoid boşluğa bölünmesi sırasında anormal gelişiminin olduğu düşünülmektedir. ${ }^{9}$
AK'ler en sık orta fossada izlenir ve tüm inrakranial kitlelerin \%1'ni oluşturur. Asemptomatik olan AK'lere travma ve baş ağrısı gibi şikayetler nedeniyle çekilen kranial BTMR ile insidental olarak tanı konulmaktadır. Semptomatik olan AK'li hastalar ise yaygın olarak kafa içi basıncının artmasına bağlı baş ağrısı, bulantı, kusma ve bilinç bozukluğu sebebiyle hastaneye başvurmaktadırlar. Semptomatik olan AK'lerin tanısı da semptomatik olmayan AK'ler gibi kranial BT-MR ile konmaktadır.

AK'lerin en sık komplikasyonu KSDH gelişmesidir.7 SDH ile ilişkili AK ilk kez 1938 yılında Davidoff ve Dyke tarafından tarif edilmiştir. AK'li hastalarda yıllık SDH oluşmas1 \%1 olduğu söylense de birçok AK’li hastaya kranial BTMR çekilmediği için tanı konulamadığı düşünülmektedir. Parsch ve arkadaşları (ark.) subdural hematom ve effüzyonu olan 658 hasta arasında $16(\% 2,4)$ 'sının AK ile ilişkili olduğunu tespit etmiştir.

Page ve ark. AK ile ilişkili SDH sebebini iki teoriyle açıklamıştır. ${ }^{5}$ Birinci teori kist duvarındaki köprü venlerinin yırtılmasıyla oluşan kanama; ikincisi ise travmayı takiben normal beyin kompliansindan daha az olan AK membranın yırtılması sonucu meydana gelen kanamadır.

Mori ve ark. AK'ler, subdural alanda boşluğa neden olup, komşu serebral venleri desteksiz bırakırlar. Desteksiz kalan venler kafa travmalarından sonra yırtılarak SDH oluşmasına sebep olur. AK'lerin orta fossada sık olmasını, orta fossada hem subdural boşluğun geniş olması hem de köprü venlerinden zengin olması açıklamaktadır.

AK ile ilişkili SDH tanısı kranial BT-MR ile konulmaktadır. ${ }^{3,10}$ Kranial MR'da T1 de AK'ler izointens SDH hiperintens görülmektedir. Ameliyat sonrası takipte de kranial BT ve MR bize kistin boyutu ve kanamanın takibi hakkında bilgi verir. Bizde hastalarımıza kranial BT-MR ile tanı koyduk. Bizim birinci olgumuzun ilk başvurusunda, kranial BT'sinde sol temporal bölgedeki izodens görünümlü AK'in rüptüre olup, sol paryetal bölgeye açıldığı ve orta 
hat şifti oluşturduğu izlenmiştir. İkinci başvurusunda kranial BT'de ilkinden farklı olarak sol temporal bölgeden paryetal bölgeye açılmış olan kist içeriğinin görüntüsü kanama ile uyumlu olan izo-hiperdense dönüştügü tespit edilmiştir. Hasta taburcu olduktan sonra yapılan kontrol BT'de sadece temporal bölgede hipodens görünümlü kist içeriği gözlendi.

AK ile ilişkili SDH tedavisinde farklı seçenekler olup bunlar; burr hole ya da kraniotomi ile SDH boşaltılması, endoskopiyle kist fenestrasyonu ve SDH boşaltılması, burr hole ya da kraniotomiyle SDH boşaltılması sonrası kistoperitoneal şant takılmasıdır., ${ }^{3,10}$ Tedavide en sık kullanılan ve çoğu yazarın önerdiği uygulama burr hole ile SDH boşaltılmasıdır. Diğer tedavi seçenekleri burr hole ile SDH drenajının başarısız olduğu durumlarda önerilmektedir.10 Bizim hastalarımızdan birini motosiklet kazasına bağlı kafa travması sonrası yatırdık. AK kanama olmadan subdural aralığa açıldığı için öncelikle takip ettik. Takibinin 15. gününde ikinci bir travma olmadan subdural bölgede kanama gelişti. Hastanın kanaması 2 adet burr hole ile hematom drenajı yapılarak tedavi edildi (Şekil 1c). Diğer hastamızda travma tespit edilmedi. Orta fossa yerleşimi olmayan sol frontoparyetal yerleşimli SDH, sol frontal ve paryetal bölgeye 1'er adet burr hole açılıp hematom drenajı yapılarak tedavi edildi (Şekil 2c). Hematom drenajından sonra yapılan kontrol BT'de sol frontal yerleşimli AK tespit edildi.

Bazı çalışmalar AK boyutlarının burr hole ile SDH drenaj1 sonrası küçüldüğünü göstermektedir. ${ }^{3}$ Bizim iki hastamızda da erken takip olduğu için kontrollerinde küçülme yoktu.

Literatür taraması incelendiğinde 2011-2020 yılları arasında 49 hastaya yapılan tedavi yaklaşımları tablo 1'de özetlenmiştir. Buna göre hastaların kliniği SDH’a bağlıysa öncelikle burr hole ile drenaj yapılması önerilmiştir (49 hastanın 29'u bu şekilde tedavi edilmiş). Hastaların klinik durumuna sadece SDH değil, AK’ler de etki ediyorsa (özel- likle bası etkisi oluşturuyorsa) bu durumlarda kraniotomi, kist fenestrasyonu, membran rezeksiyonu, kistoperitoneal şant takılması gibi tedavi seçenekleri uygulanabilmektedir (49 hastanın 16 'sı bu şekilde tedavi edilmiştir). Bizde AK ile ilişkili SDH'ı olan 2 vakamızı burr hole yoluyla drene ederek tedavi ettik.

\section{SONUÇ}

AK ile ilişkili KSDH'lu hastaların kliniği çoğu zaman SDH’a bağlıdır. Bu durumda AK'e müdahale etmeden burr hole ile SDH drenaj1 yapmak hem yeterli hem de minimal invaziv bir yaklaşımdır. 
Sakarya Tip Dergisi 2021;11(3):669-674

KAYA ve Ark., Araknoid Kistler ile İlişskili Subdural Hematomlar

\section{Kaynaklar}

1. Pradilla G, Jallo G. Arachnoid cysts: case series and review of the literature. Neurosurg Focus. 2007; 22: E7.

2. Czernicki T, Marchel A, Nowak A, Bojarski P. Arachnoid cyst of the middle cranial fossa presented as subdural hematomas. Neurol Neurochir Pol. 2005; 39(4): 328-334.

3. Domenicucci M, Russo N, Giugni E, Pierallini A. Relationship between supratentorial arachnoid cyst and chronic subdural hematoma: Neuroradiological evidence and surgical treatment. J Neurosurg. 2009; 110: 1250-1255.

4. Gunduz B, Yassa MI, Ofluoglu E, Ekinci B, Erdogan U, Asilturk M, Toplamaoglu H. Two cases of arachnoid cyst complicated by spontaneous intrcystic hemorrhage. Neurol India. 2010; 58(2): 312-315.

5. Page A, Paxton RM, Mohan D. A reappraisal of the relationship between arachnoid cysts of the middle fossa and chronic subdural haematoma. J Neurol Neurosurg Psychiatry. 1987; 50: 1001-1007.
6. Bilginer B, Onal MB, Oguz KK, Akalan N. Arachnoid cyst associated with subdural hematoma: report of three cases and review of the literature. Childs Nerv Syst. 2009; 25:119-124.

7. Wester $K$, Helland CA. How often do chronic extra-cerebral haematomas occur in patients with intracranial arachnoid cysts? J Neurol Neurosurg Psychiatry. 2008; 79:72-75.

8. Hopkin J,Mamourian A, Lollis S, Duhaime T. The next extreme sport? Subdural hematoma in a patient with arachnoid cyst after head shaking competition. British Journal of Neurosurgery. 2006; 20(2): 111-113.

9. Rengachary SS, Watanabe I, Brackett CE. Pathogenesis of intracranial arachnoid cysts. Surg Neurol. 1978; 9: 139-144.

10. Ibarra R, Kesava PP. Role of MR imaging in the diagnosis of complicated arachnoid cyst. Pediatr Radiol. 2000; 30: 329-331. 